\title{
Interactions between ethylene and auxin are crucial to the control of grape (Vitis vinifera L.) berry ripening
}

\author{
Christine Böttcher, Crista A Burbidge, Paul K Boss and Christopher Davies*
}

\begin{abstract}
Background: Fruit development is controlled by plant hormones, but the role of hormone interactions during fruit ripening is poorly understood. Interactions between ethylene and the auxin indole-3-acetic acid (IAA) are likely to be crucial during the ripening process, since both hormones have been shown to be implicated in the control of ripening in a range of different fruit species.

Results: Grapevine (Vitis vinifera L.) homologues of the TRYPTOPHAN AMINOTRANSFERASE RELATED (TAR) and YUCCA families, functioning in the only characterized pathway of auxin biosynthesis, were identified and the expression of several TAR genes was shown to be induced by the pre-ripening application of the ethylene-releasing compound Ethrel. The induction of TAR expression was accompanied by increased IAA and IAA-Asp concentrations, indicative of an upregulation of auxin biosynthesis and conjugation. Exposure of ex planta, pre-ripening berries to the ethylene biosynthesis inhibitor aminoethoxyvinylglycine resulted in decreased IAA and IAA-Asp concentrations. The delayed initiation of ripening observed in Ethrel-treated berries might therefore represent an indirect ethylene effect mediated by increased auxin concentrations. During berry development, the expression of three TAR genes and one YUCCA gene was upregulated at the time of ripening initiation and/or during ripening. This increase in auxin biosynthesis gene expression was preceded by high expression levels of the ethylene biosynthesis genes 1-aminocyclopropane-1-carboxylate synthase and 1-aminocyclopropane-1-carboxylate oxidase.

Conclusions: In grape berries, members of both gene families involved in the two-step pathway of auxin biosynthesis are expressed, suggesting that IAA is produced through the combined action of TAR and YUCCA proteins in developing berries. The induction of TAR expression by Ethrel applications and the developmental expression patterns of auxin and ethylene biosynthesis genes indicate that elevated concentrations of ethylene prior to the initiation of ripening might lead to an increased production of IAA, suggesting a complex involvement of this auxin and its conjugates in grape berry ripening.
\end{abstract}

Keywords: Aminoethoxyvinylglycine, Auxin, Biosynthesis, Ethrel, Ethylene, Interaction, Vitis vinifera, Ripening

\section{Background}

The coordinated growth and development of plants relies on a wide range of control systems, including an intricate network of interactions between all classes of known plant hormones and other signalling compounds such as sugars [1-5]. Fruit ripening is an example of a developmentally controlled process that is dependent on a range of plant hormones, but our knowledge about the molecular interactions of these different classes of hormones

* Correspondence: christopher.davies@csiro.au

CSIRO Plant Industry, PO Box 350, Glen Osmond, SA 5064, Australia in the ripening process is still rudimentary (reviewed by $[6,7])$. An interesting target for the investigation of hormonal interplay in fruit is the interaction between the gaseous hormone ethylene and the auxin class of hormones, of which indole-3-acetic acid (IAA) is the most abundant member. Ethylene plays a crucial role in the ripening of climacteric fruit which display a sharp increase in ethylene production and respiratory activity at the onset of ripening (reviewed by [8]), but its relevance for the ripening of nonclimacteric fruit, which lack the dramatic, ripening-related change in ethylene formation and respiration, is still unclear (reviewed by [6]). A moderate increase in ethylene

\section{() Biomed Central}


concentration and respiration rate has been demonstrated for the non-climacteric strawberry (Fragaria ananassa Duch.) [9], but both events occurred after the transition into the ripening phase. The only reports of small peaks in ethylene concentration just before the initiation of ripening in non-climacteric fruit come from Litchi chinensis Sonn. [10] and grape (Vitis vinifera L.) [11-13]. In grape, a role for ethylene is further evidenced by the developmental expression profiles of genes encoding for the ethylene biosynthesis enzymes 1-aminocyclopropane-1-carboxylate synthase (ACS) and 1-aminocyclopropane-1-carboxylate oxidase (ACO), which describe a pre-ripening expression for $A C S$ [14] and a peak in transcript accumulation for $A C O[12,14]$ a short time before the initiation of ripening (called 'veraison' in grape berries).

Interestingly, in contrast to what is known from climacteric fruit, the treatment of pre-veraison grape berries with the ethylene-releasing compound Ethrel has been shown to delay ripening [15-17]. The Ethrel-induced delay in the onset of sugar and anthocyanin accumulation resembles the ripening-delaying effects caused by the pre-veraison application of auxins [18-23], which have emerged as another important factor in fruit ripening in both climacteric and non-climacteric fruit (reviewed by [6,7]). In climacteric fruit, such as tomato (Solanum lycopersicum Mill.) $[24,25]$, or banana (Musa paradisiaca L.) [26] and in nonclimacteric fruit like strawberry $[27,28]$ and grape [29-32] the concentrations of IAA before and during ripening were generally found to be low. In all four fruit species mentioned above, as well as in many other climacteric and non-climacteric fruit, the application of natural or synthetic auxins during the pre-ripening stage of fruit development has often been found to lead to a ripening delay (reviewed by [6]) and therefore auxins are widely viewed as ripening inhibitors [24,26,29,33]. In contrast IAAamide conjugates have been reported to accumulate in ripening bananas [26], muskmelons (Cucumis melo L.) [34] and strawberries [27]. More detailed studies in grape berries have revealed that the concentration of IAA-Asp, an IAA-amide conjugate linked to IAA degradation [35] and formed by the action of IAA-amido synthetases (Gretchen Hagen (GH3) proteins) [36], increased sharply at veraison and remained at high concentrations throughout the ripening phase [29]. A similar pattern of IAA-Asp accumulation has been found in tomato which suggests a more complex role for auxins in fruit ripening that requires further investigation [29].

The best understood interaction between auxin and ethylene is the induction of ethylene biosynthesis by applied auxins, which was first described by Morgan and Hall [37] who reported that 2,4-dichlorophenoxyacetic acid application led to an increase in ethylene production in cotton plants. It was later revealed that exogenous auxins induce the transcription of ACS genes in mung beans (Vigna radiata (L.) Wilczek) [38]. A similar induction of $A C S$ expression and in some instances also $A C O$ expression has since been demonstrated for many other plant species, including Arabidopsis (Arabidopsis thaliana L.) [39-41], a range of climacteric and nonclimacteric fruit such as apple (Malus domestica Borkh.) [42], pear (Pyrus communis L.) [43], peach (Prunus persica (L.) Batsch) [44] and grape [45]. Reports about an acceleration of at least parts of the ripening process by auxin treatments in some climacteric fruit [46-50] can therefore be interpreted as an indirect auxin effect mediated through the induction of ethylene biosynthesis $[42,44,48]$.

The complementary effect of ethylene on auxin biosynthesis has long remained elusive, due to an incomplete understanding of the molecular mechanisms involved in the biosynthesis of IAA. A dependence of ethylene action on IAA biosynthesis, perception, signalling and transport has been illustrated in studies using Arabidopsis mutants and auxin measurements [51,52]. Furthermore, the induction of genes encoding for anthranilate synthase and tryptophan synthase subunits as well as a $\mathrm{GH} 3$ protein by ethylene treatments has been reported [53,54]. However, only the recent elucidation of the main IAA biosynthesis pathway in Arabidopsis has revealed the full extent of the regulation of auxin biosynthesis by ethylene and the dependence of ethylene effects on auxin production. Three independent studies [55-57] have provided evidence that IAA is synthesised via a simple two-step pathway in which the family of TRYPTOPHAN AMINOTRANSFERASE OF ARABIDOPSIS1/TRYPTOPHAN AMINOTRANSFERASE RELATED (TAA1/TAR) proteins $[58,59]$ converts tryptophan to indole-3-pyruvate which is then converted to IAA by the YUCCA (YUC) family of flavin-containing monooxygenases [60]. The existence of a TAR/YUC pathway has also been confirmed in maize (Zea mays L.) where it is essential for normal vegetative and reproductive development [61]. The expression of TAA1 as well as some TARs in roots and apical hooks of Arabidopsis seedlings can be induced by ethylene treatments and the restricted expression of TAA1/TAR genes leading to local IAA production is thought to be the basis of tissue-specific ethylene effects [58].

The above introduction shows that auxins and ethylene are involved in berry ripening and that their application can alter the progression of ripening. In this study, evidence is provided for a functional TAR/YUC pathway of auxin biosynthesis in developing grape berries which is at least in part regulated by ethylene. Auxin measurements as well as gene expression studies in Ethreltreated fruit suggest that the Ethrel-induced ripening delay in grapes might be mediated by increased auxin concentrations in pre-ripening fruit. In developing berries 
an increase in the expression of ethylene biosynthesis genes precedes elevated transcript levels of auxin biosynthesis and conjugation genes at around the initiation of ripening, indicative of a role for ethylene/auxin interactions in the control of berry ripening.

\section{Results and discussion}

Pre-veraison Ethrel treatment of grape berries leads to ripening delay and increased auxin concentrations

In grape berries, the initiation of ripening can be delayed by the pre-veraison application of the ethylene-releasing compound Ethrel [15-17] and auxins [18-23]. The similar effects of Ethrel and auxins on the ripening behaviour of grapes combined with the increasing evidence for complex interactions between ethylene and IAA (reviewed by $[62,63]$ ) is suggestive of a link between these two plant hormones in the control of ripening. In order to investigate the possibility of an ethylene/auxin interaction in grape berry ripening, pre-veraison Shiraz berries were treated with either Ethrel or a Control solution in two consecutive seasons. In the 2011 trial, the Ethrel treatment of berries 20 days pre-veraison (veraison is defined as the sampling date immediately prior to a significant increase in total soluble solids (TSS) measured using a refractometer) delayed the onset of ripening by 13 days (veraison of Control berries was 3 February 2011). The Ethrel-treated berries had significantly lower TSS values between 31 and 54 days post spray (dps) and at $67 \mathrm{dps}$ when compared with the Control berries (Figure 1A) and there was also a reduction in berry weight between 37 and 54 dps (Figure 1B).
In 2012, veraison of the Control berries (24 January 2012) occurred one week earlier than predicted, which brought the two successive treatments that were applied during that season close to the veraison date (eight and one day prior to veraison). In previous studies, Ethreltreatments within a week of veraison had no effect on sugar accumulation and berry weight [15]. Accordingly, the ripening-delaying effect of Ethrel in the 2012 trial was less pronounced than what had been observed in 2011. Veraison of the Ethrel-treated berries was only delayed by seven days. However, from 15 days post initial spray (dpis) onwards the TSS values in the Ethrel-treated berries were significantly lower when compared with the Control berries (Figure 1C) and a difference in berry weight was observed 22 and 29 dpis when the Ethreltreated berries were significantly lighter (Figure 1D).

A time course of berry samples from both trials was used to determine if the Ethrel treatments had caused changes in the concentrations of IAA and its most abundant amino acid conjugate, IAA-Asp [29]. For the 2011 experiment this was done 3-48 hours post spray (hps), which was extended for the 2012 trial to test for differences in auxin concentrations from one hour post initial spray (hpis) through to the time point of veraison of the Ethrel-treated berries.

When compared with the Control fruit at each time point, IAA and IAA-Asp concentrations in the 2011 experiment were only significantly different from the Ethreltreated berries at the last time point analysed (48 hps), where the IAA concentration was increased approximately ten-fold (Figure 2A) and the IAA-Asp concentration


Figure 1 Delayed ripening of Shiraz berries after treatment with Ethrel. Changes in TSS, measured as degrees Brix, in field grown Shiraz berries treated (A) once in 2011 (20 days pre-veraison) or (C) twice in 2012 (8 and 1 days pre-veraison) with $300 \mathrm{HL} \mathrm{L}^{-1}$ Ethrel in $0.1 \%$ (V/V) Chemwet 1000 or $0.1 \%$ (v/V) Chemwet 1000 (Control). The same berry samples were used to measure changes in berry weight in (B) the 2011 and (D) the 2012 samples. Control, closed circles with solid lines; Ethrel, closed triangles with dashed line. All data represent means $\pm S E(n=3)$. Asterisks indicate significant differences of the mean values of Ethrel-treated samples from the mean values of Control samples as determined with Student's $t$-test $\left({ }^{*} p<0.05,{ }^{* *} p<0.01\right)$. 


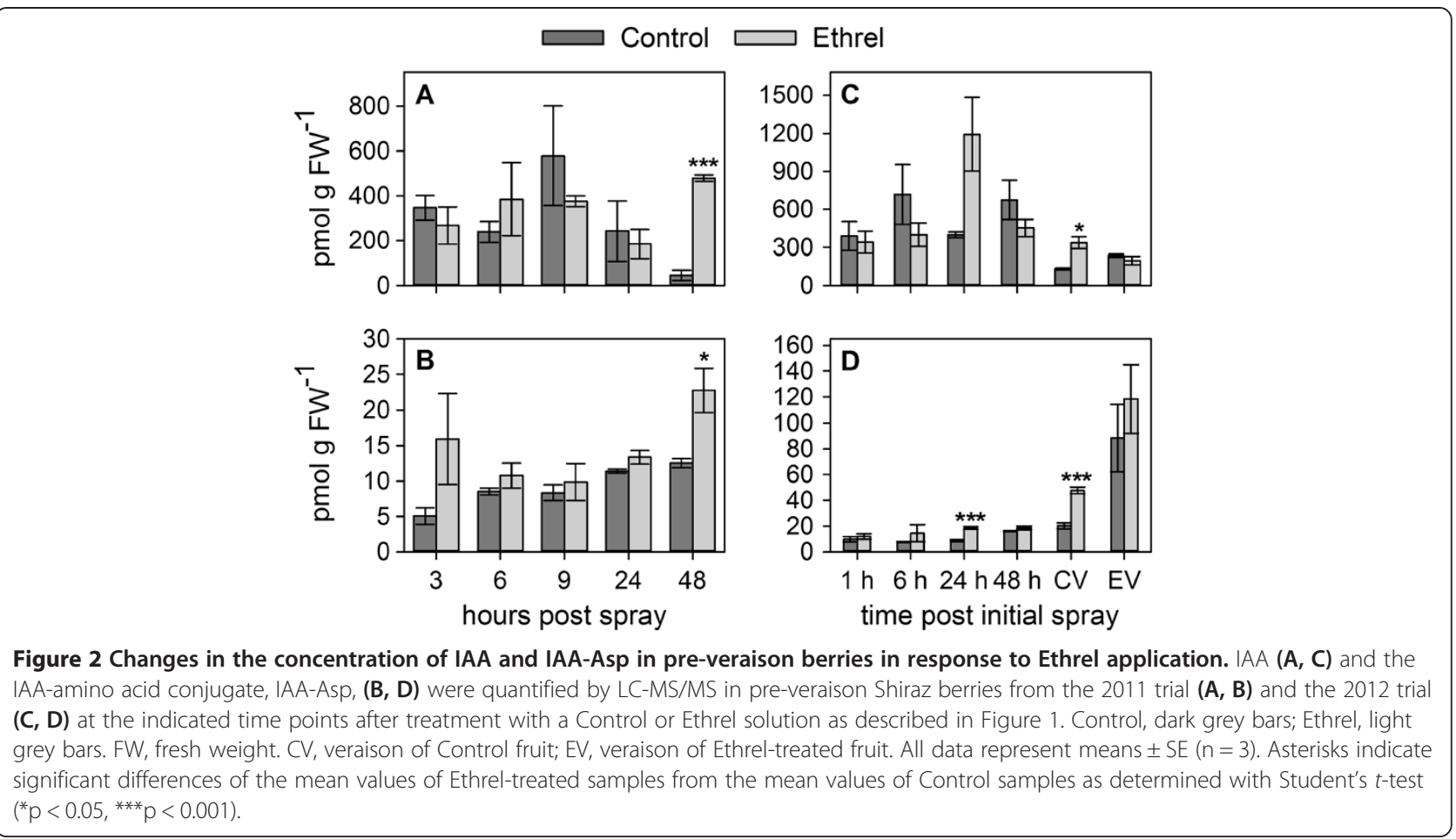

approximately two-fold (Figure 2B) in response to Ethrel. In the 2012 samples the IAA concentration was significantly higher in the Ethrel-treated berries when the Control berries were going through veraison $(\sim$ three-fold) (Figure 2C) and IAA-Asp concentrations were increased by Ethrel about two-fold 24 hpis and at veraison of the Control berries (Figure 2D).

The presented data provide evidence for an Ethrelmediated increase in the accumulation of free and conjugated IAA in pre-veraison grape berries. The lasting elevation of auxin concentrations up to the transition into the ripening phase poses the question whether the Ethrel-induced ripening delay might be the result of higher than normal auxin concentrations in pre-veraison berries.

\section{IAA and IAA-Asp levels and grape homologues of auxin biosynthesis genes are upregulated in berries by Ethrel while auxin levels are repressed by aminoethoxyvinylglycine}

Recent studies on Arabidopsis seedlings have provided evidence that ethylene is involved in the establishment of local auxin maxima by inducing the expression of TAA1 and related genes (TARs) [58]. Together with YUC proteins TAA1/TARs are a component of the only complete pathway of auxin biosynthesis in plants described to date [55-57]. In order to investigate if the increase in auxin concentrations in Ethrel-treated grape berries might be due to a stimulation of the TAR/YUC pathway, grapevine homologues of the Arabidopsis TAA1 and YUC1 proteins were identified through a BLASTP similarity search on the NCBI database. The resulting nine TAR and ten YUC grapevine sequences were aligned to the respective protein families from Arabidopsis and unrooted phylogenetic trees were constructed from the alignments (Figure 3A, B). Any further analyses were restricted to those members of the grapevine families that were verified as being expressed in any tissues by the presence of ESTs in the NCBI database. These were VvTAR1 (55\% identity with AtTAA1), VvTAR2 (59\% identity with AtTAR2), VvTAR3 (53\% identity with AtTAR3) and VvTAR4 (55\% identity with AtTAR3) (Figure 3A), as well as VvYUC1 (49\% identity with AtYUC10), VvYUC2 (51\% identity with AtYUC10) and VvYUC3 (73\% identity with AtYUC4) (Figure 3B). All attempts to amplify $V v Y U C 2$ fragments from a number of different grapevine cDNAs (from flowers, berries at different stages, roots, leaves) for the generation of qRT-PCR standards failed (data not shown), so this gene could not be included in expression analyses.

The expression of the putative auxin biosynthesis genes from the TAR and YUC families, as well as the previously described grapevine GH3 genes (GH3-1 and GH3-2) involved in IAA-Asp formation in berries $[19,29,64]$, was analysed in the same samples that had been used for the quantitation of IAA and IAA-Asp (see above, Figure 2A-D). To verify the activation of an ethylene response in the Ethrel-treated berries, the expression of the ethylene biosynthesis genes ACS1 and $A C O 1$ as well as the expression of the ethylene receptor 




gene ETR2 was also analysed. In a previous study on grape berries, ACS1 expression was not changed by Ethrel treatments three weeks to one week prior to veraison, whereas the expression of ACO1 and ETR2 was Ethrel-inducible between three and two weeks pre-veraison [15]. ETR2 is commonly used as a marker for ethylene responses that has been employed in research on vegetative tissues [65] as well as fruit [66].
In the 2011 experiment, a strong response to Ethrel was demonstrated by the induction of ETR2 expression, by up to 20-fold, 3-48 h after the Ethrel spray (Additional file 1A). The expression of ACS1 ( 9 and $24 \mathrm{hps}$ ) and ACO1 (9-48 hps) was also upregulated (two to 13-fold) (Additional file 1A). The expression of YUC3 was not detectable in any of the samples analysed. The transcription of TAR2 was increased up to 30 -fold in 
Ethrel-treated berries between 3-24 hps (Figure 4). There was also an induction (two to three-fold) of TAR4 at $24 \mathrm{hps}$ and $48 \mathrm{hps}$, whereas the expression of TAR 1 and TAR3 was not significantly different between the Control and Ethrel samples at all time points (Figure 4). As for TAR1 and TAR3 there was no significant difference in the expression of $Y U C 1$ at any of the tested time points between the Ethreltreated and the Control berries (Figure 4). Similar to TAR4, GH3-1 expression was significantly upregulated by the Ethrel treatment after $24 \mathrm{~h}$ and $48 \mathrm{~h}$ (up to 4.5 -fold). The transcription of GH3-2 was also induced at $3 \mathrm{hps}$ (five-fold) and at 9-48 hps (up to four-fold) (Figure 4). The increase in GH3 expression as well as TAR4 expression correlated with the higher IAA-Asp and IAA concentrations in Ethrel-treated berries $48 \mathrm{hps}$ (Figure 2A, B). The highly elevated expression of TAR2 preceded the increase in free IAA and conjugate concentrations after $48 \mathrm{~h}$. This could be due to a lag between the increase in transcript levels and the production of active enzyme, but it might also reflect break down of IAA and/or IAAAsp, sequestration of IAA into conjugates other than IAA-Asp or transport of auxins out of the berry.

In the 2012 experiment, where only a minor delay in ripening of the Ethrel-treated berries was observed, the expression analysis of ACS1, ACO1 and ETR2 also reflected a weak response to Ethrel (Additional file 1B). All three genes were only found to have a significant increase in transcription at one time point. Accordingly, the changes in expression of the IAA biosynthesis and conjugation genes were also less pronounced than in the previous season. As in 2011, TAR1 expression was similar in Control berries and Ethrel-treated fruit. However,
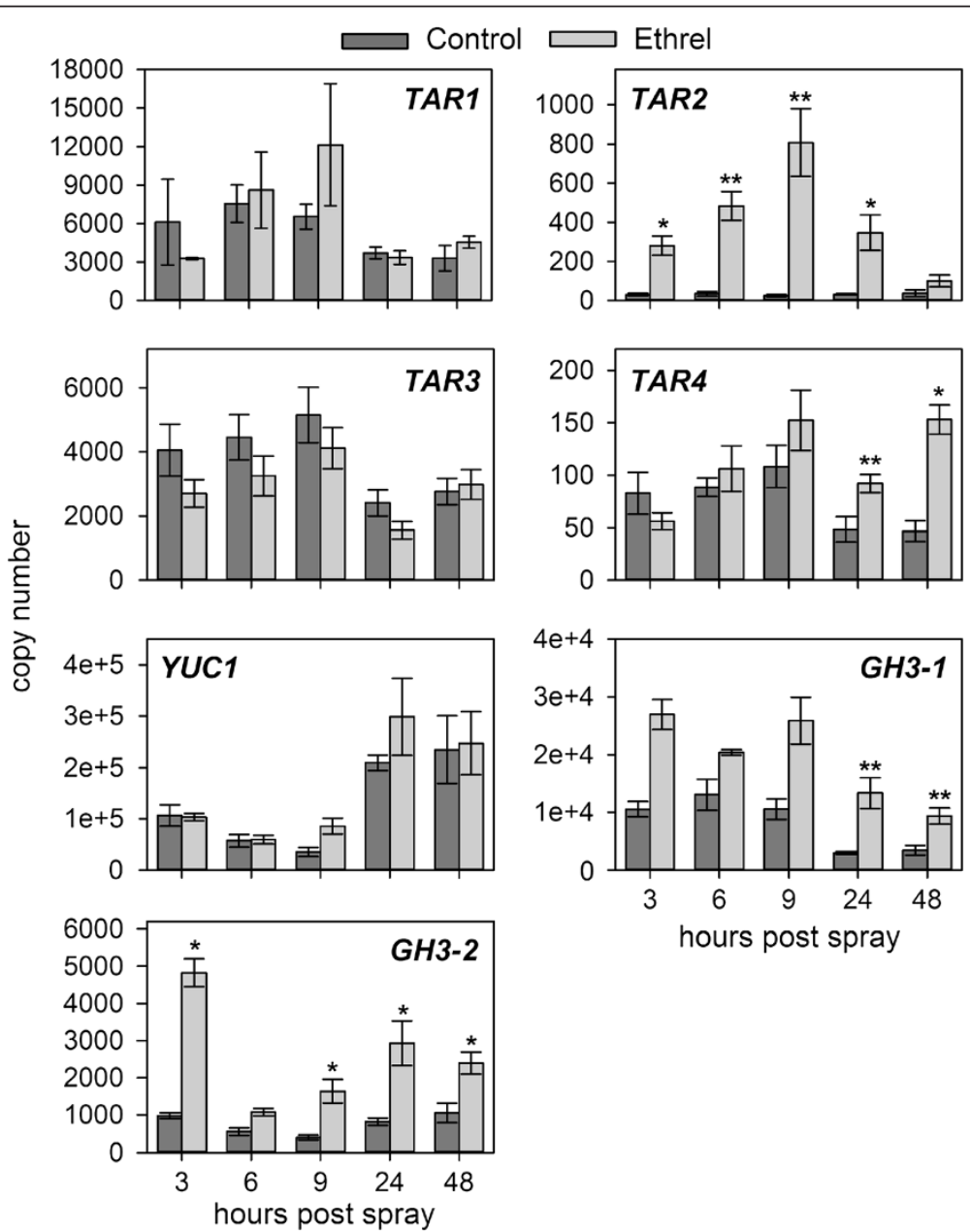

Figure 4 Transcription of selected auxin biosynthesis and GH3 genes in response to Ethrel in the 2011 trial. The expression of TAR1-TAR4, YUC1, GH3-1 and GH3-2 in pre-veraison Shiraz berries from the 2011 trial was analysed by qRT-PCR at the indicated time points after treatment with a Control or Ethrel solution (see Figure 1). Control, dark grey bars; Ethrel, light grey bars. All data represent means $\pm S E(n=3)$. Asterisks indicate significant differences of the mean values of Ethrel-treated samples from the mean values of Control samples as determined with Student's t-test $\left({ }^{*} p<0.05,{ }^{* *} p<0.01\right)$. 
there was a significant reduction in TAR1 transcript abundance in Ethrel-treated berries $6 \mathrm{hpis}$ and at the time of veraison of the Ethrel-treated fruit (Figure 5). There was no significant change in expression of TAR2 between Ethrel-treated berries and Control berries (Figure 5). There were two-times more TAR3 transcripts in Ethreltreated fruit as the berries were going through veraison and the expression of TAR4 was increased by the Ethrel treatment $24 \mathrm{hpis}$ and at the time point of veraison of the Control berries (two-fold) (Figure 5). The elevated expression of TAR4 coincided with the slight increase in free IAA concentration at veraison of the Control berries (Figure 2C). YUC1 expression was reduced by the Ethrel treatment 48 hpis (Figure 5) and YUC3 expression could not be detected. The expression of both GH3 genes was increased by about three-fold $1 \mathrm{~h}$ after the initial Ethrel spray. There was also an induction of GH3-1 expression 48 hpis and the transcript accumulation of GH3-2 was increased in the Ethrel-treated berries at the time of veraison in the Control and the Ethrel-treated fruit (Figure 5).

In a recent study on the effects of ethylene on grape berry ripening, it was found that aminoethoxyvinylglycine (AVG), an inhibitor of ethylene biosynthesis, had a ripening-advancing effect on berries when applied between three to one weeks prior to veraison [15]. AVG has long been known to be a competitive inhibitor of ACS proteins $[67,68]$, thereby blocking the conversion of S-adenosyl-methionine to 1-aminocyclopropane-1carboxylic acid [69]. When Capitani et al. [70] solved the crystal structure of an apple ACS protein, it was revealed that the active site of this enzyme is highly similar to that of the related family of aminotransferases [71]. In accordance with this finding, AVG has recently been described as an inhibitor of auxin biosynthesis in Arabidopsis with the TAA1/TAR family as its target [72]. Independent of ethylene, AVG treatments led to a

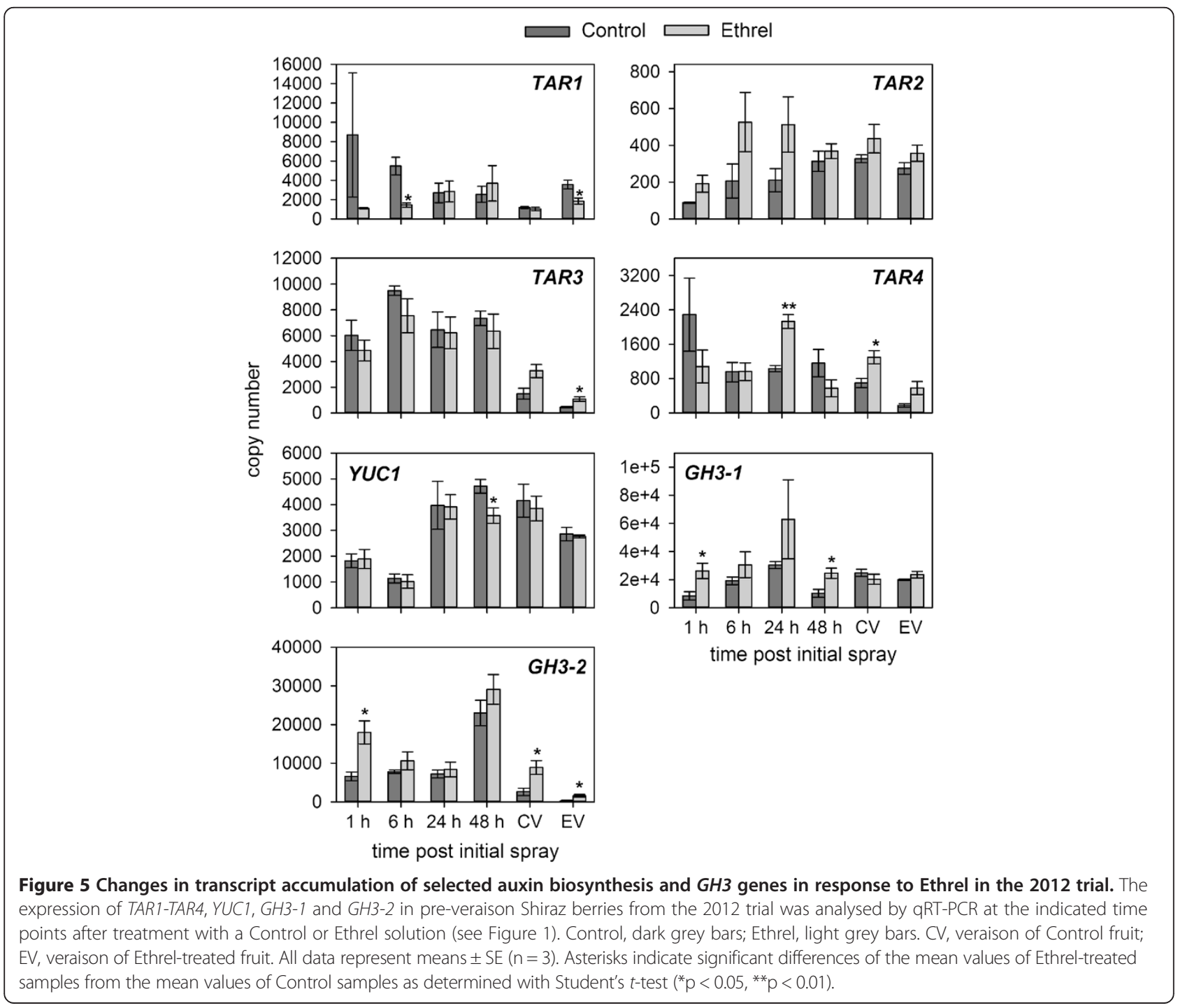


rapid reduction in the concentration of free IAA in Arabidopsis seedlings and in leaves of tomato and tobacco (Nicotiana tabacum L.) plants in a dose-dependent manner. The results of this study confirmed earlier reports about a $50-60 \%$ reduction in the rate of IAA biosynthesis in Arabidopsis seedlings exposed to AVG [52]. Based on these recent data on AVG action, the effect of AVG on auxin production in pre-veraison Shiraz berries was investigated in an ex planta experiment. Berries were exposed to AVG, Ethrel and a Control treatment for $0.5-24 \mathrm{~h}$ followed by the extraction and quantitation of IAA and IAA-Asp. Already at the first time point of analysis ( $0.5 \mathrm{~h}$ after the initiation of treatment) a two-fold increase in the concentration of IAA was found in the Ethrel-treated berries, whereas a threefold reduction in the concentration of IAA was measured in AVG-treated fruit (Figure 6A). The Ethrel-induced increase in IAA accumulation was transient and only lasted for $1 \mathrm{~h}$ after which the IAA concentration returned to levels observed in the Control and even slightly decreased after $24 \mathrm{~h}$ of exposure. However, AVG caused a significant reduction in IAA concentrations after 6-24 h of exposure (Figure 6A). A similar, but delayed, trend was observed for changes in the IAA-Asp concentrations (Figure 6B). Exposure to Ethrel resulted in a significant increase in IAA-Asp accumulation after $1 \mathrm{~h}$ and $3 \mathrm{~h}$, whereas the treatment with AVG led to a reduced IAA-Asp concentration after $6 \mathrm{~h}$ (two-fold). The rapid changes in auxin concentrations in response to Ethrel and AVG in the ex planta experiment when compared with the data obtained from berries that were sprayed in the field (see above, Figure 2) is most likely due to a higher uptake rate of the compounds under the ex planta conditions and to continuous exposure to high levels. It can therefore be inferred that changes in auxin biosynthesis and conjugation occurred within the first 30 min of exposure, which explains the unchanged expression of the TAR, YUC and GH3 genes analysed between 0.5 and $24 \mathrm{~h}$ of exposure (Figure $6 \mathrm{C}$ ). There was also no difference in the expression of $A C S 1$ and $A C O 1$ between Control, Ethrel-treated and AVG-treated berries (Additional file 1C). The only significant change in ETR2 expression occurred at $3 \mathrm{~h}$ after Ethrel exposure (two-fold increase) (Additional file $1 \mathrm{C}$ ). A repression of $A C O 1$ and ETR2 expression by AVG after $20 \mathrm{~h}$ of exposure has been reported from a similar grape berry ex planta experiment [15]. Since both these genes are sucrose-responsive [15], this apparently conflicting result is most likely due to the different sucrose concentrations used in the previous study $(0 \%$ or $12 \%(\mathrm{w} / \mathrm{v}))$ compared with this study $(3 \%(\mathrm{w} / \mathrm{v}))$.

It can be concluded that the TAR/YUC pathway of auxin biosynthesis is active in grape berries and can be stimulated by increased concentrations of ethylene. As a consequence, ripening-delay by Ethrel may be mediated by elevated auxin formation in the berry tissue. More studies are needed to determine if the advancement of berry ripening by AVG applications is the result of decreased ethylene or auxin concentrations or possibly of both.

\section{Changes in the expression of auxin and ethylene biosynthesis genes during development suggest a role for both hormones in the initiation of grape berry ripening}

Previous studies on grape berries as well as other nonclimacteric fruit have reported low concentrations of free IAA and ethylene at the time of ripening initiation (reviewed by [6]). However, a subtle increase in ethylene concentrations coinciding with the beginning of the ripening phase in L. chinensis and grapes [10-13], as well as a drastic increase in the accumulation of IAA-Asp in ripening grapes and tomatoes [29], suggest that both hormones might be of importance for the transition from the pre-ripening to the ripening stage. To further investigate the implications of ethylene and auxin in grape berry ripening, the expression of TAR1-4, YUC1, YUC3 as well as ACS1 and ACO1 was analysed in Shiraz berries from 3 weeks post flowering (wpf) through to harvest at 16 wpf. Veraison, defined as the last time point before a significant increase in TSS levels was observed, was found to be $8 \mathrm{wpf}$ (Figure 7A). It also marked the start of the second growth phase and the accumulation of anthocyanins (Figure 7B, C). TAR1 was expressed at low levels in pre-veraison berries, but copy numbers increased rapidly between 10-12 wpf and remained high through to harvest after 16 weeks (Figure 7D). TAR3 was expressed in pre-veraison berries, whereas the expression profiles of TAR2 and TAR4 were characterized by a significant peak in transcript levels at veraison (TAR4) or one week post-veraison (TAR2) (Figure 7D). A comparable peak in expression was also observed for YUC1 (8-10 wpf) (Figure 7D), whereas YUC3 was found to be expressed at very low levels in young berries (one and two wpf), but YUC3 transcripts could not be reliably detected in berries 3-16 wpf (data not shown). An increase in the expression of YUC genes, similar to $Y U C 1$, has recently been reported in strawberries, where the transcript accumulation of FaYUC1 and FaYUC2 in achenes peaked at the large green fruit stage [73]. In grape berries, the increase in expression of the putative auxin-biosynthesis genes was preceded by high expression levels of the ethylene biosynthesis genes $A C S 1$ (3-7 wpf) and $A C O 1$ (peaking at $7 \mathrm{wpf}$ ) (Figure 7D) which confirmed previous results for the expression of $A C S / A C O$ in developing grape berries $[12,14,15]$. Similar expression patterns of all eight genes were recorded from a 3-16 wpf berry series from Cabernet Sauvignon (Additional file 2). 

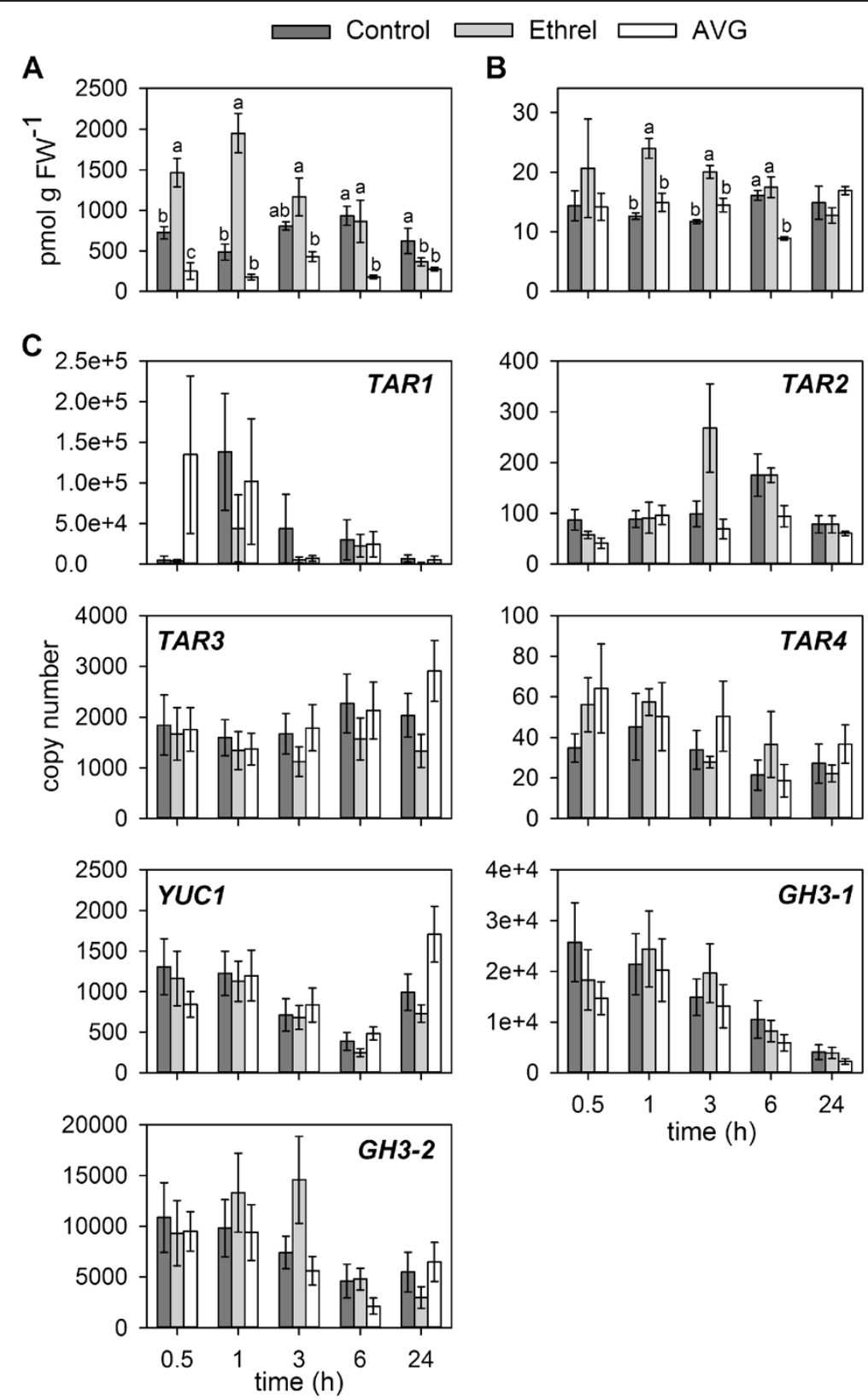

Figure 6 Effect of Ethrel and AVG on auxin concentrations and the expression of selected auxin biosynthesis and GH3 genes in an ex planta experiment. IAA (A) and the IAA-amino acid conjugate, IAA-Asp, (B) were quantified by LC-MS/MS in ex planta pre-veraison Shiraz berries exposed to ReTain (125 mg L-1 AVG, 3\% (w/v) sucrose), Ethrel (72 $\mathrm{mg} \mathrm{L}^{-1}$ ethephon, 3\% (w/v) sucrose), or Control (3\% (w/v) sucrose) conditions for the indicated periods of time. FW, fresh weight. (C) Using the same tissues the expression of TAR1-TAR4, YUC1, GH3-1 and GH3-2 was analysed by qRT-PCR. Control, dark grey bars; Ethrel, light grey bars; AVG, white bars. Bars represent means $\pm S E(n=3)$ and are denoted by a different letter if the means for each time point differ significantly $(p<0.05)$ using one-way ANOVA followed by Duncan's post hoc test.

The data suggest that a peak in auxin biosynthesis coincides with the initiation of ripening in grape berries and that this elevated auxin production might be induced by ethylene. The post-veraison expression of TAR1 further indicates that IAA is synthesized throughout the ripening period. An increase in IAA biosynthesis at and after veraison seems to contradict the low concentrations of this auxin in ripening berries as well as the ripening-delaying effects of high levels of auxins in pre-veraison berries. However, the sharp increase in IAA-Asp accumulation just after veraison reported by Böttcher et al. [29] might indicate that all IAA produced during a short period around the start of ripening and possibly throughout ripening is sequestered via the conjugation pathway. This proposal is supported by the increased expression of GH3-1 during this time in berry 

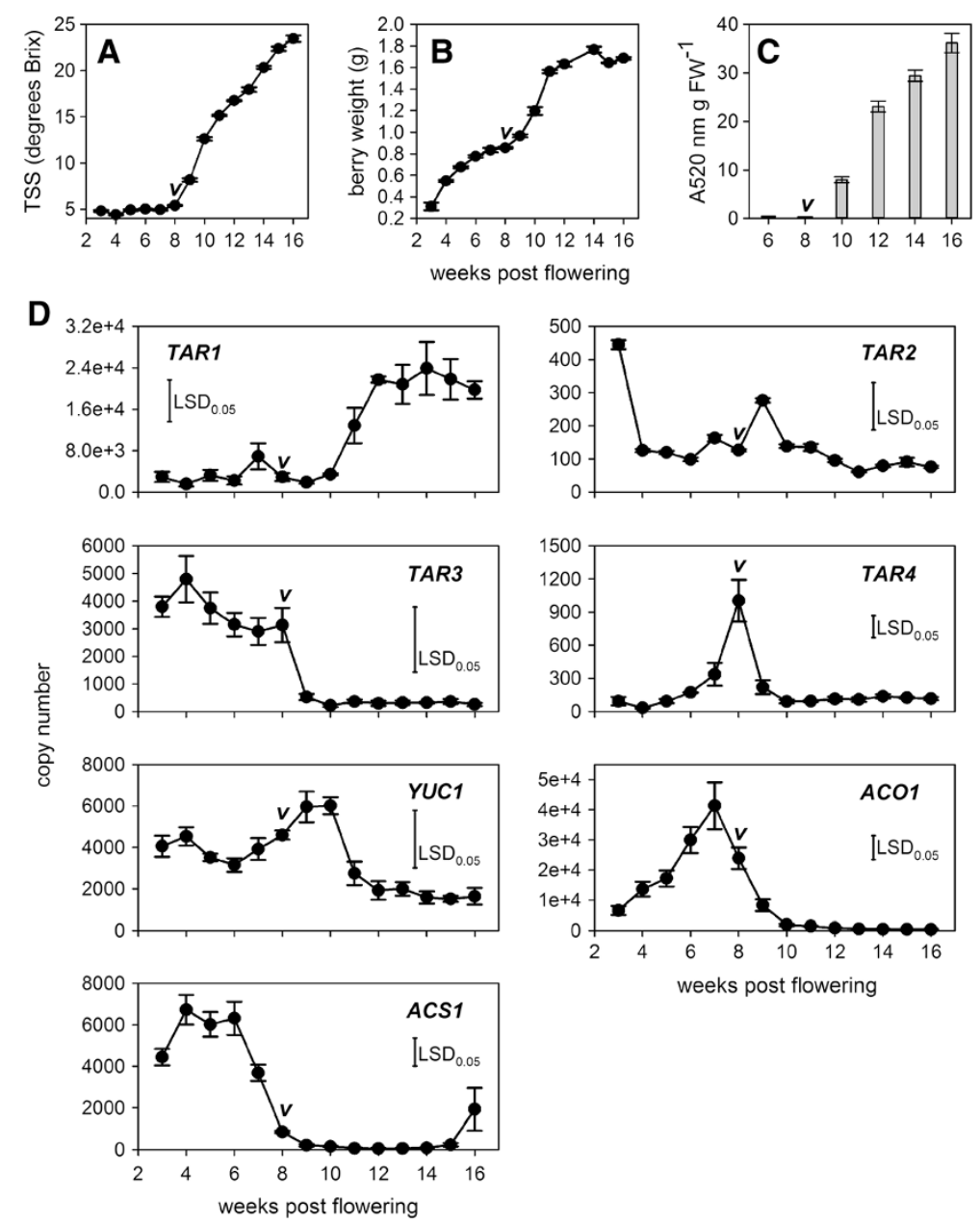

Figure 7 Expression profiles of selected auxin and ethylene biosynthesis genes throughout Shiraz berry development. The development of field-grown Shiraz berries was documented by changes in (A) TSS, (B) berry weight and (C) anthocyanin (A520 nm) accumulation. (D) Between 3-16 wpf the expression of TAR1-TAR4, YUC1, ACS1 and ACO1 was analysed by qRT-PCR. " $V$ " indicates veraison as determined by the last time point before a significant increase (ANOVA followed by Duncan's post hoc test) in TSS levels was recorded. All data represent means \pm SE $(n=3)$ and for the gene expression data LSD values were determined at the $p<0.05$ significance level.

development. Furthermore, in tomatoes, which also display increased concentrations of IAA-Asp during ripening [29], the overexpression of a pepper (Capsicum chinense L.) $\mathrm{GH} 3$ gene stimulated an early transition into the ripening phase upon an ethylene stimulus [74] and the RNAi suppression of APETALA2, a negative regulator of ripening [75], resulted in earlier ripening and an increased accumulation of GH3 transcripts [76]. The long-held view that IAA-amino acid conjugates are merely means to store or degrade the free auxin [77] has been challenged by a number of studies that provide evidence for an active role of IAA-Asp and other conjugates in plant development and disease response (reviewed by [78]). It is therefore conceivable that the IAA-Asp conjugate might represent a ripening signal in grapes, and possibly also in other fruit species, which can be perceived at a certain developmental stage of the fruit by an as yet unknown mechanism. From the presented data, a possible role of ethylene in the ripening of grape berries could be the triggering of IAA synthesis and subsequent IAA-Asp formation at the above mentioned critical developmental stage. Removal of the ethylene trigger should consequently lead to ripening inhibition. This hypothesis is supported by studies from Chervin et al. [12,79], where blocking of ethylene perception close to veraison led to reduced berry size and delayed anthocyanin and sugar accumulation.

\section{Conclusions}

Despite an increasing knowledge of the involvement of ethylene and IAA in fruit development, information about interactions between these two hormones in fruit is limited. The present study provides evidence of a functional two-step pathway of auxin biosynthesis in grape berries and demonstrates its activation by the 
ethylene-releasing compound Ethrel. An observed ripening delay in Ethrel-treated fruit might therefore be due to increased auxin concentrations in pre-ripening fruit. The expression patterns of auxin and ethylene biosynthesis genes during berry development further suggest that an increase in ethylene production prior to the initiation of ripening stimulates IAA biosynthesis at the commencement of ripening. This developmentally controlled induction of auxin biosynthesis by ethylene might be required for the rapid accumulation of the proposed ripening factor, IAA-Asp.

\section{Methods}

\section{Plant material}

Ethrel treatments were performed using Vitis vinifera $\mathrm{L}$. cv Shiraz fruit in two consecutive years at the same site (Hahndorf, South Australia, -35.018223, 138.838220). In 2011, pre-veraison berries were sprayed to run off once (14 January 2011, 20 days pre-veraison) with $300 \mu \mathrm{L} \mathrm{L}^{-1}$ Ethrel (144 mg L ${ }^{-1}$ ethephon; Bayer CropScience, East Hawthorn, Australia) in 0.1\% (v/v) Chemwet 1000 (Nufarm, Laverton, Australia), solution $\mathrm{pH}$ 3.1. Control fruit were sprayed with a $0.1 \%(\mathrm{v} / \mathrm{v})$ Chemwet 1000 solution. There was $0.2 \mathrm{~mm}$ precipitation during the $48 \mathrm{~h}$ period after spraying and the average maximum temperature during this period was $29.5^{\circ} \mathrm{C}$. The trial was of a randomised triplicate design, the sample size per replicate and treatment was 30 bunches. Samples of 60 randomly harvested berries per replicate were taken 3, 6, 9, 24 and $48 \mathrm{~h}$ after the sprays. Berries were weighed, immediately deseeded, frozen in liquid nitrogen and stored at $-80^{\circ} \mathrm{C}$ until used. Throughout development weekly samples of 60 randomly harvested berries per replicate were used to measure berry weight and TSS.

In 2012, pre-veraison berries were sprayed twice (16 January 2012, 8 days pre-veraison and 23 January 2012, 1 day pre-veraison) with Control and Ethrel solutions as described above. There was no precipitation during the $48 \mathrm{~h}$ period after spraying and the average maximum temperature during this period was $34.5^{\circ} \mathrm{C}$. Other changes to the 2012 trial design and sampling regime were as follows: the sample size was increased to 400 bunches per replicate and treatment, samples of 60 berries for deseeding and freezing were taken 1, 6, 24 and $48 \mathrm{~h}$ after the initial spray as well as at the developmental stages corresponding to veraison of the Control and veraison of the Ethrel-treated berries and 80 berries per replicates were used for weight and TSS measurements.

For the analysis of developmental changes in gene expression Vitis vinifera L. cv Cabernet Sauvignon and Shiraz berries from 3-16 wpf were collected at weekly intervals, (22 November 2010-15 March 2011) from a commercial vineyard (Willunga, South Australia- $35^{\circ} .26$, $138^{\circ} .55$ ) in the $2010 / 2011$ season. Sampling was completed between 09:30 and 11:30, berries (60-200 berries sampled at each time point) were immediately deseeded and tissue frozen in liquid nitrogen and stored at $-80^{\circ} \mathrm{C}$ until used.

For the ex planta berry experiment 40 bunches from ten vines (Vitis vinifera L. cv Shiraz) were sampled from a vineyard in the Adelaide Hills (Hahndorf, South Australia, -35.018223, 138.838220) 19 days (05 January 2012) before veraison between 09:00 and 10:00 and kept on ice until used.

\section{Determination of anthocyanin and TSS levels}

Individual measurements of TSS (degrees Brix) were taken for the berries sampled from the Ethrel experiments in 2011 and 2012 with an RFM710 digital refractometer (Bellingham Stanley, Tunbridge Wells, UK). TSS analysis and anthocyanin measurements for the berries from the developmental series were done as described by Böttcher et al. [20].

\section{Phylogenetic analysis}

TAR- and YUC-related grapevine sequences were identified by BLASTP searches of the non-redundant NCBI protein database $\left(\mathrm{E}\right.$-value $\left.\leq 10^{-20}\right)$ using either the Arabidopsis TAA1 or YUC1 protein sequence as the query. NCBI accession numbers for all sequences used in the phylogenetic analysis are listed either in Figure 3 or in Additional file 3 . The sequences were aligned using the ClustalW (version 2.0.12) program [80] in the multiple alignment mode and the neighbour-joining unrooted tree was generated with PHYLIP 3.67 [81].

\section{RNA extraction, CDNA synthesis and qRT-PCR}

Total RNA was extracted from grape berry tissue according to Davies and Robinson [82] and further purified as described by Symons et al. [83]. First-strand cDNA for qRT-PCR was synthesized with Transcriptor Reverse Transcriptase (Roche Diagnostics, Mannheim, Germany) using $1 \mu \mathrm{g}$ of RNA and the Oligo $(\mathrm{dT})_{18}$ primer in a reaction volume of $20 \mu \mathrm{L}$ following the manufacturer's instructions. Prior to use cDNA samples were diluted 20 -fold. qRT-PCR analyses were performed using the Roche LightCycler 480 SYBR Green I Master kit with $15 \mu \mathrm{L}$ reactions and a final primer concentration of $0.5 \mu \mathrm{M}$. The amplification was performed using the Roche LightCycler 480 system with the following parameters: $5 \mathrm{~min}$ at $95^{\circ} \mathrm{C}, 20 \mathrm{~s} 95^{\circ} \mathrm{C}, 20 \mathrm{~s} 58^{\circ} \mathrm{C}$ and $20 \mathrm{~s}$ $72^{\circ} \mathrm{C}$ (45 cycles), $5 \mathrm{~min}$ at $72^{\circ} \mathrm{C}$, followed by a melt cycle $\left(15 \mathrm{~s}\right.$ at $95^{\circ} \mathrm{C}, 45 \mathrm{~s}$ at $50^{\circ} \mathrm{C}$, continuous heating to $95^{\circ} \mathrm{C}$ at $\left.0.11^{\circ} \mathrm{C} \mathrm{s}^{-1}\right)$. The gene-specific primer pairs and corresponding accession numbers used for GH3-1, GH3-2, ACS1, $A C O 1$, ETR2 as well as ACT2 (reference gene) have been published previously $[15,19]$. The primers used for putative auxin biosynthesis genes were: for TAR1 [GenBank: XM_002274511], 5'-CATCTATTCAAGATACTATTGG-3' 
and 5'-ATATTGCAGCTACTCTCAAT-3', for TAR2 [GenBank: XM_002281372], 5'-CAGCAATGAAGCATATTGA AGG-3' and 5' -GAGTGAGAGCACCAGGAAATG-3', for TAR3 [GenBank: XM_002265837], 5'-CCCAAGATGACT TTGATATGCTG-3' and 5' ${ }^{\prime}$-TGATCAACTGATTGTTGA TTCCACT-3', for TAR4 [GenBank: XM_002266102], $5{ }^{\prime}$-CAGCCTCATCAAGACCCAAGAT-3' and 5' -TGA CGGTTGATTTCATTCTTCG-3', for YUC1[GenBank: XM_002269808], 5'-CAGGAAACTGTCGCAATAGTGG-3' and $5^{\prime}$-CAAGAACTATGTTGGGTATTGAGAGG-3', for YUC2 [GenBank: XM_002269727], 5'-TACACTTTGG AAGCATCACAGC-3' and 5' -GGTTTGTACTGTGCT GGACTGG-3' and for YUC3 [GenBank: XM_002282321], 5'-ATGCCCAAAACGCCATTTCC-3' and 5'-ATGTCCC GGGCGATATTGAC-3'. Each PCR was performed in triplicate. To calculate the copy number of the genes in each reaction, the purified gene fragments used for the standard curves were quantified using PicoGreen (AGRF, Adelaide, South Australia) and the number of molecules in each standard dilution was determined according to Whelan et al. [84]. The specificity of the reactions was confirmed by melt curve analysis as well as separation on agarose gels and the identity of each product was verified by sequencing (AGRF, Adelaide, South Australia).

\section{Ex planta berry induction assay}

Randomly picked berries from the sampled bunches were sterilized in $0.1 \%(\mathrm{v} / \mathrm{v})$ Chemwet 1000 containing half of a Milton antibacterial tablet $\mathrm{L}^{-1}$ (Milton Australia, Laverton North, Victoria) for $10 \mathrm{~min}$ and washed three times with sterile nanopure water. All the following procedures were carried out in a laminar flow under sterile conditions. A thin slice was removed from the base of each berry by cutting horizontally through the brush area to facilitate compound absorption and the modified berries were placed on agar. Twenty berries were placed on petri dishes filled with $25 \mathrm{~mL}$ of Gamborg's media, $0.025 \%(\mathrm{w} / \mathrm{v})$ casein hydrosylate, $0.8 \%(\mathrm{w} / \mathrm{v})$ agar, $\mathrm{pH} 5.7-$ 5.8 and one or more of the following additives (final concentrations), respectively: ReTain (125 mg L $\mathrm{m}^{-1}$ AVG, filter sterilised), Ethrel (72 $\mathrm{mg} \mathrm{L}^{-1}$ ethephon), 3\% (w/v) sucrose. Each plate constituted a replicate and three replicates per treatment and time point were used.

Berries were placed on the plates with the cut surface facing the agar, the plates were sealed with Parafilm and kept in the dark at room temperature. All plates containing Ethrel were stored separately. After 0.5-24 h the berries were harvested, deseeded and frozen in liquid nitrogen.

\section{Chemical synthesis of labelled IAA-Asp}

[Indole- $\mathrm{D}_{5}$ ] IAA-Asp was synthesized as described previously [29] using [indole- $\mathrm{D}_{5}$ ]-labelled IAA as starting substrate.

\section{LC-ESI-MS/MS analysis of IAA and IAA-Asp}

For LC-MS/MS quantification, IAA and conjugates were extracted and quantified from $100 \mathrm{mg}$ of grape berry tissue as described by Böttcher et al. [29].

\section{Statistical data analysis}

The significance of any differences between samples was tested by Student's $t$-test (unpaired) or ANOVA with Duncan's post hoc test, using IBM SPSS Statistics ver. 20 (IBM Australia, Sydney, NSW, Australia).

\section{Additional files}

\begin{abstract}
Additional file 1: Transcription of the ethylene biosynthesis genes, $A C S 1$ and $A C O 1$, and the ethylene receptor gene ETR2 in response to Ethrel. (A) The expression of ACS1, ACO1 and ETR2 in pre-veraison (Shiraz berries from the 2011 trial was analysed by qRT-PCR at the indicated time points after treatment with a Control or Ethrel solution (single treatment (20 days pre-veraison)). Control, dark grey bars; Ethrel, light grey bars. All data represent means $\pm S E(n=3)$. Asterisks indicate significant differences of the mean values of Ethrel-treated samples from the mean values of Control samples as determined with Student's $t$-test $\left({ }^{*} p<0.05,{ }^{* *} p<0.01\right)$. (B) The expression of ACS1, ACO1 and ETR2 in pre-veraison Shiraz berries from the 2012 trial was analysed by qRT-PCR at the indicated time points after treatment with a Control or Ethrel solution (two treatments (8 and 1 day pre-veraison)). Control, dark grey bars; Ethrel, light grey bars. $\mathrm{CV}$, veraison of Control fruit; $\mathrm{EV}$, veraison of Ethrel-treated fruit. All data represent means $\pm S E(n=3)$. Asterisks indicate significant differences of the mean values of Ethrel-treated samples from the mean values of Control samples as

determined with Student's $t$-test $\left({ }^{* *} p<0.01\right)$. (C) The expression of ACS1, ACO1 and ETR2, analysed using $\mathrm{QRT} T-P C R$, in ex planta pre-veraison Shiraz berries exposed to ReTain (125 $\mathrm{mg} \mathrm{L}^{-1}$ AVG, 3\% (w/v) sucrose), Ethrel (72 $\mathrm{mg} \mathrm{L}^{-1}$ ethephon, 3\% (w/v) sucrose), or Control (3\% (w/v) sucrose) conditions for the indicated periods of time. Control, dark grey bars; Ethrel, light grey bars; AVG, white bars. Bars represent means $\pm S E(n=3)$ and are denoted by a different letter if the means differ significantly $(p<0.05)$ using one-way ANOVA followed by Duncan's post hoc test.
\end{abstract}

Additional file 2: Expression profiles of selected auxin and ethylene biosynthesis genes throughout Cabernet Sauvignon berry development. The development of field-grown Cabernet Sauvignon berries was documented by changes in (A) TSS, (B) berry weight and (C) anthocyanin (A520 nm) accumulation. All data represent means \pm SE $(n=3)$. (D) Between 3-16 wpf the expression of TAR1-TAR4, YUC1, ACS1 and ACO1 was analysed by qRT-PCR. The expression data are shown for two biological replicates. n.d., not detected. " $V$ " indicates veraison as determined by the last time point before a significant increase (ANOVA followed by Duncan's post hoc test) in TSS levels was recorded.

Additional file 3: GenBank accession numbers of the Arabidopsis protein sequences used for the phylogenetic analysis.

\section{Abbreviations}

ACO: 1-aminocyclopropane-1-carboxylate oxidase; ACS: 1 aminocyclopropane-1-carboxylate synthase; AVG: Aminoethoxyvinylglycine; Dps: Days post spray; Dpis: Days post initial spray; CV: veraison of Control fruit; FW: Fresh weight; EV: veraison of Ethrel-treated fruit; GH3: Gretchen Hagen3; Hpis: Hours post initial spray; IAA: Indole-3-acetic acid; TAA: TRYPTOPHAN AMINOTRANSFERASE OF ARABIDOPSIS; TAR: TRYPTOPHAN AMINOTRANSFERASE RELATED; TSS: Total soluble solids; YUC: YUCCA.

\section{Competing interests}

The authors declare that they have no competing interests. 


\section{Authors' contributions}

All authors contributed to the sampling and processing of berry samples derived from field-based and ex planta experiments. CB participated in the design of the study, carried out the phylogenetic analyses, primer design and auxin measurements and drafted the manuscript. CAB carried out the qRT-PCR analyses and participated in the auxin extractions. PKB participated in the design of the study and performed the statistical analyses. CD conceived of the study and participated in its design and coordination. All authors read and approved the final manuscript.

\section{Acknowledgements}

The authors would like to thank Angela Keulen for technical assistance. We also thank Chalk Hill Wines and Nepenthe Wines for providing the fruit used in this study. This project was partly funded by Australia's grape growers and winemakers through their investment body the Grape and Wine Research and Development Corporation (grant no. CSP 09/05) with matching funding from the Australian Federal Government. CSIRO Plant Industry is a partner of the Wine Innovation Cluster.

Received: 26 August 2013 Accepted: 20 December 2013

Published: 23 December 2013

\section{References}

1. Rashotte AM, Chae HS, Maxwell BB, Kieber JJ: The interaction of cytokinin with other signals. Physiol Plant 2005, 123(2):184-194.

2. Rolland F, Moore B, Sheen J: Sugar sensing and signaling in plants. Plant Cell 2002, 14(suppl 1):S185-S205.

3. Teale WD, Ditengou FA, Dovzhenko AD, Li X, Molendijk AM, Ruperti B, Paponov I, Palme K: Auxin as a model for the integration of hormonal signal processing and transduction. Mol Plant 2008, 1(2):229-237.

4. Weiss D, Ori N: Mechanisms of cross talk between gibberellin and other hormones. Plant Physiol 2007, 144(3):1240-1246.

5. Zhang S, Wei Y, Lu Y, Wang X: Mechanisms of brassinosteroids interacting with multiple hormones. Plant Signal Behav 2009, 4(12):1117-1120.

6. Böttcher C, Davies C: Hormonal control of grape berry development and ripening. In The Biochemistry of the Grape Berry, vol. 1. Edited by Gerós H, Chaves MM, Delrot S. Sharjah: Bentham Science; 2012:194-217.

7. Vendrell $M$, Palomer $X$ : Hormonal control of fruit ripening in climacteric fruit. Acta Hortic 1998, 463:325-334.

8. Tucker GA: Introduction. In Biochemistry of Fruit Ripening. Edited by Seymour GB, Taylor JE, Tucker GA. London: Chapman and Hall; 1993:1-51.

9. lannetta PPM, Laarhoven L-J, Medina-Escobar N, James EK, McManus MT, Davies HV, Harren FJM: Ethylene and carbon dioxide production by developing strawberries show a correlative pattern that is indicative of ripening climacteric fruit. Physiol Plant 2006, 127(2):247-259.

10. Wang $H$, Huang $H$, Huang $X$ : Differential effects of abscisic acid and ethylene on the fruit maturation of Litchi chinensis Sonn. Plant Growth Regul 2007, 52(3):189-198.

11. Alleweldt G, Koch R: Ethylene content in ripening grape berries. Vitis 1977, 16:263-271.

12. Chervin C, El-Kereamy A, Roustan J-P, Latché A, Lamon J, Bouzayen M: Ethylene seems required for the berry development and ripening in grape, a non-climacteric fruit. Plant Sci 2004, 167(6):1301-1305.

13. Düring $H$, Alleweldt $G$, Koch $R$ : Studies on hormonal control of ripening in berries and grape vines. Acta Hortic 1978, 80:397-405.

14. Pilati S, Perazzolli M, Malossini A, Cestaro A, Demattè L, Fontana P, Dal Ri A, Viola R, Velasco R, Moser C: Genome-wide transcriptional analysis of grapevine berry ripening reveals a set of genes similarly modulated during three seasons and the occurrence of an oxidative burst at vèraison. BMC Genomics 2007, 8(1):428.

15. Böttcher C, Harvey KE, Boss PK, Davies C: Ripening of grape berries can be advanced or delayed by reagents that either reduce or increase ethylene levels. Funct Plant Biol 2013, 40(6):566-581.

16. Coombe $B G$, Hale CR: The hormone content of ripening grape berries and the effects of growth substance treatments. Plant Physiol 1973, 51(4):629-634

17. Hale CR, Coombe BG, Hawker JS: Effects of ethylene and 2-chloroethylphosphonic acid on the ripening of grapes. Plant Physio/ 1970, 45(5):620-623.

18. Ban T, Ishimaru M, Kobayashi S, Shiozaki S, Goto-Yamamoto N, Horiuchi S: Abscisic acid and 2,4-dichlorophenoxyacetic acid affect the expression of anthocyanin biosynthetic pathway genes in 'Kyoho' grape berries. J Hortic Sci Biotechnol 2003, 78:586-589.
19. Böttcher C, Boss PK, Davies C: Acyl substrate preferences of an IAA-amido synthetase account for variations in grape (Vitis vinifera L.) berry ripening caused by different auxinic compounds indicating the importance of auxin conjugation in plant development. J Exp Bot 2011, 62(12):4267-4280.

20. Böttcher C, Harvey K, Forde CG, Boss PK, Davies C: Auxin treatment of pre-veraison grape (Vitis vinifera L.) berries both delays ripening and increases the synchronicity of sugar accumulation. Aust J Grape Wine Res 2011, 17(1):1-8.

21. Böttcher C, Boss PK, Davies C: Delaying Riesling grape berry ripening with a synthetic auxin affects malic acid metabolism and sugar accumulation, and alters wine sensory characters. Funct Plant Biol 2012, 39(9):745-753.

22. Davies C, Boss PK, Robinson SP: Treatment of grape berries, a nonclimacteric fruit with a synthetic auxin, retards ripening and aters the expression of developmentally regulated genes. Plant Physiol 1997 115(3):1155-1161.

23. Hale CR: Growth and senescence of the grape berry. Aust J Agric Res 1968, 19(6):939-945

24. Buta JG, Spaulding DW: Changes in indole-3-acetic acid and abscisic acid levels during tomato (Lycopersicon esculentum Mill.) fruit development and ripening. J Plant Growth Regul 1994, 13(3):163-166.

25. Mapelli S, Frova C, Torti G, Soressi GP: Relationship between set, development and activities of growth regulators in tomato fruits. Plant Cell Physiol 1978, 19(7):1281-1288.

26. Purgatto E, Oliveira do Nascimento JR, Lajolo FM, Cordenunsi BR: The onset of starch degradation during banana ripening is concomitant to changes in the content of free and conjugated forms of indole-3-acetic acid. J Plant Physiol 2002, 159(10):1105-1111.

27. Archbold DD, Dennis FG Jr: Quantification of free ABA and free and conjugated IAA in strawberry achene and receptacle tissue during fruit development. J Am Soc Hortic Sci 1984, 109:330-335.

28. Symons GM, Chua Y-J, Ross JJ, Quittenden LJ, Davies NW, Reid JB: Hormonal changes during non-climacteric ripening in strawberry. J Exp Bot 2012, 63(13):4741-4750.

29. Böttcher C, Keyzers RA, Boss PK, Davies C: Sequestration of auxin by the indole-3-acetic acid-amido synthetase GH3-1 in grape berry (Vitis vinifera L.) and the proposed role of auxin conjugation during ripening. $J$ Exp Bot 2010, 61(13):3615-3625

30. Cawthon DL, Morris JR: Relationship of seed number and maturity to berry development, fruit maturation, hormonal changes, and uneven ripening of 'Concord' (Vitis labrusca L.) grapes. J Am Soc Hortic Sci 1982, 107(6):1097-1104

31. Inaba A, Ishida M, Sobajima $Y$ : Changes in endogenous hormone concentrations during berry development in relation to the ripening of Delaware grapes. J Jpn Soc Hortic Sci 1976, 45(3):245-252.

32. Zhang X, Luo G, Wang R, Wang J, Himelrick DG: Growth and developmental responses of seeded and seedless grape berries to shoot girdling. J Am Soc Hortic Sci 2003, 128(3):316-323.

33. Frenkel C: Involvement of peroxidase and indole-3-acetic acid oxidase isozymes from pear, tomato, and blueberry fruit in ripening. Plant Physiol 1972, 49(5):757-763.

34. Dunlap JR, Slovin JP, Cohen JD: Indole-3-acetic acid, ethylene, and abscisic acid metabolism in developing muskmelon (Cucumis melo L.) fruit. Plant Growth Regul 1996, 19(1):45-54

35. Östin A, Kowalyczk M, Bhalerao RP, Sandberg G: Metabolism of indole-3-acetic acid in Arabidopsis. Plant Physiol 1998, 118(1):285-296.

36. Staswick PE, Serban B, Rowe M, Tiryaki I, Maldonado MT, Maldonado MC Suza W: Characterization of an Arabidopsis enzyme family that conjugates amino acids to indole-3-acetic acid. Plant Cell 2005, 17(2):616-627

37. Morgan PW, Hall WC: Effect of 2,4-dichlorophenoxyacetic acid on the production of ethylene by cotton and grain sorghum. Physiol Plant 1962, 15(3):420-427

38. Yoshii H, Imaseki $\mathrm{H}$ : Regulation of auxin-induced ethylene biosynthesis. Repression of inductive formation of 1-aminocyclopropane-1-carboxylate synthase by ethylene. Plant Cell Physiol 1982, 23(4):639-649.

39. Abel S, Nguyen MD, Chow W, Theologis A: ASC4, a primary indoleacetic acid-responsive gene encoding 1-aminocyclopropane-1-carboxylate synthase in Arabidopsis thaliana: Structural characterization, expression in Escherichia coli, and expression characteristics in response to auxin. J Biol Chem 1995, 270(32):19093-19099. 
40. Raghavan C, Ong EK, Dalling MJ, Stevenson TW: Regulation of genes associated with auxin, ethylene and ABA pathways by 2,4-dichlorophenoxyacetic acid in Arabidopsis. Funct Integr Genomics 2006, 6(1):60-70.

41. Tsuchisaka A, Theologis A: Unique and overlapping expression patterns among the Arabidopsis 1-amino-cyclopropane-1-carboxylate synthase gene family members. Plant Physiol 2004, 136:2982-3000.

42. Li J, Yuan R: NAA and ethylene regulate expression of genes related to ethylene biosynthesis, perception, and cell wall degradation during fruit abscission and ripening in 'Delicious' apples. J Plant Growth Regul 2008, 27(3):283-295.

43. Kondo S, Isuzugawa K, Kobayashi S, Mattheis J: Aroma volatile emission and expression of 1-aminocyclopropane-1-carboxylate (ACC) synthase and ACC oxidase genes in pears treated with 2,4-DP. Postharvest Biol Technol 2006, 41(1):22-31.

44. Trainotti L, Tadiello A, Casadoro G: The involvement of auxin in the ripening of climacteric fruits comes of age: The hormone plays a role of its own and has an intense interplay with ethylene in ripening peaches. J Exp Bot 2007, 58(12):3299-3308.

45. Ziliotto F, Corso M, Rizzini FM, Rasori A, Botton A, Bonghi C: Grape berry ripening delay induced by a pre-véraison NAA treatment is paralleled by a shift in the expression pattern of auxin- and ethylene-related genes. BMC Plant Biol 2012, 12(1):185.

46. Agustí M, Gariglio N, Castillo A, Juan M, Almela V, Martínez-Fuentes A, Mesejo C: Effect of the synthetic auxin 2,4-DP on fruit development of loquat. Plant Growth Regul 2003, 41(2):129-132.

47. Agustí M, Juan M, Mesejo C, Martínez-Fuentes A, Almela V: Persimmon fruit size and climacteric encouraged by 3,5,6-trichloro-2-pyridyloxyacetic acid. J Hortic Sci Biotechnol 2004, 79(2):171-174.

48. Kondo S, Settsu K, Jitratham A: How application times of 2,4-DP influence the ripening capacity of 'La France' pears. HortScience 2004, 39(1):101-104.

49. Ohmiya A: Effects of auxin on growth and ripening of mesocarp discs of peach fruit. Sci Hortic 2000, 84(3-4):309-319.

50. Yuan R, Carbaugh DH: Effects of NAA, AVG, and 1-MCP on ethylene biosynthesis, preharvest fruit drop, fruit maturity, and quality of 'Golden Supreme' and 'Golden Delicious' apples. Hortscience 2007, 42(1):101-105.

51. Rüžička K, Ljung K, Vanneste S, Podhorská R, Beeckman T, Friml J, Benková E: Ethylene regulates root growth through effects on auxin biosynthesis and transport-dependent auxin distribution. Plant Cell 2007, 19(7):2197-2212.

52. Swarup R, Perry P, Hagenbeek D, Van Der Straeten D, Beemster GTS, Sandberg G, Bhalerao R, Ljung K, Bennett MJ: Ethylene upregulates auxin biosynthesis in Arabidopsis seedlings to enhance inhibition of root cell elongation. Plant Cell 2007, 19(7):2186-2196.

53. Stepanova AN, Hoyt JM, Hamilton AA, Alonso JM: A link between ethylene and auxin uncovered by the characterization of two root-specific ethylene-insensitive mutants in Arabidopsis. Plant Cell 2005, 17(8):2230-2242.

54. Zhong GY, Burns JK: Profiling ethylene-regulated gene expression in Arabidopsis thaliana by microarray analysis. Plant Mol Biol 2003, 53(6):117-131.

55. Mashiguchi K, Tanaka K, Sakai T, Sugawara S, Kawaide H, Natsume M, Hanada A, Yaeno T, Shirasu K, Yao H, et al: The main auxin biosynthesis pathway in Arabidopsis. Proc Natl Acad Sci 2011, 108(45):18512-18517.

56. Stepanova AN, Yun J, Robles LM, Novak O, He W, Guo H, Ljung K, Alonso JM: The Arabidopsis YUCCA1 flavin monooxygenase functions in the indole-3-pyruvic acid branch of auxin biosynthesis. Plant Cell 2011, 23(11):3961-3973.

57. Won C, Shen X, Mashiguchi K, Zheng Z, Dai X, Cheng Y, Kasahara H, Kamiya Y, Chory J, Zhao $Y$ : Conversion of tryptophan to indole-3-acetic acid by TRYPTOPHAN AMINOTRANSFERASES OF ARABIDOPSIS and YUCCAs in Arabidopsis. Proc Natl Acad Sci 2011, 108(45):18518-18523.

58. Stepanova AN, Robertson-Hoyt J, Yun J, Benavente LM, Xie D-Y, Doležal K, Schlereth A, Jürgens G, Alonso JM: TAA1-mediated auxin biosynthesis is essential for hormone crosstalk and plant development. Cell 2008, 133(1):177-191.

59. Tao Y, Ferrer J-L, Ljung K, Pojer F, Hong F, Long JA, Li L, Moreno JE, Bowman ME, Ivans $L J$, et al: Rapid synthesis of auxin via a new tryptophan-dependent pathway is required for shade avoidance in plants. Cell 2008, 133(1):164-176.

60. Zhao Y, Christensen SK, Fankhauser C, Cashman JR, Cohen JD, Weigel D, Chory J: A role for flavin monooxygenase-like enzymes in auxin biosynthesis. Science 2001, 291(5502):306-309.

61. Phillips KA, Skirpan AL, Liu X, Christensen A, Slewinski TL, Hudson C, Barazesh S, Cohen JD, Malcomber S, McSteen P: vanishing tassel2 encodes a grass-specific tryptophan aminotransferase required for vegetative and reproductive development in Maize. Plant Cell 2011, 23(2):550-566.
62. Muday GK, Rahman A, Binder BM: Auxin and ethylene: collaborators or competitors? Trends Plant Sci 2012, 17(4):181-195.

63. Stepanova AN, Alonso JM: Ethylene signaling and response: where different regulatory modules meet. Curr Opin Plant Biol 2009, 12(5):548-555.

64. Peat TS, Böttcher C, Newman J, Lucent D, Cowieson N, Davies C: Crystal structure of an indole-3-acetic acid amido synthetase from grapevine involved in auxin homeostasis. Plant Cell 2012, 24(11):4525-4538.

65. Binder BM, O'Malley RC, Wang W, Moore JM, Parks BM, Spalding EP, Bleecker $A B$ : Arabidopsis seedling growth response and recovery to ethylene. A kinetic analysis. Plant Physiol 2004, 136(2):2913-2920.

66. Ireland HS, Yao J-L, Tomes S, Sutherland PW, Nieuwenhuizen N, Gunaseelan K, Winz RA, David KM, Schaffer RJ: Apple SEPALLATA1/2-like genes control fruit flesh development and ripening. Plant J 2013, 73(6):1044-1056.

67. Boller T, Herner RC, Kende H: Assay for and enzymatic formation of an ethylene precursor, 1-aminocyclopropane-1-carboxylic acid. Planta 1979, 145(3):293-303.

68. Yamagami T, Tsuchisaka A, Yamada K, Haddon WF, Harden LA, Theologis A Biochemical diversity among the 1-amino-cyclopropane-1-carboxylate synthase isozymes encoded by the Arabidopsis gene family. J Biol Chem 2003, 278(49):49102-49112.

69. Adams DO, Yang SF: Ethylene biosynthesis: Identification of 1-aminocyclopropane-1-carboxylic acid as an intermediate in the conversion of methionine to ethylene. Proc Natl Acad Sci 1979, 76(1):170-174.

70. Capitani G, Hohenester E, Feng L, Storici P, Kirsch JF, Jansonius JN: Structure of 1-aminocyclopropane-1-carboxylate synthase, a key enzyme in the biosynthesis of the plant hormone ethylene. J Mol Biol 1999, 294(3):745-756.

71. Theologis A: One rotten apple spoils the whole bushel: The role of ethylene in fruit ripening. Cell 1992, 70(2):181-184.

72. Soeno K, Goda H, Ishii T, Ogura T, Tachikawa T, Sasaki E, Yoshida S, Fujioka S, Asami T, Shimada Y: Auxin biosynthesis inhibitors, identified by a genomics-based approach, provide insights into auxin biosynthesis. Plant Cell Physiol 2010, 51(4):524-536.

73. Liu H, Ying Y-Y, Zhang L, Gao Q-H, Li J, Zhang Z, Fang J-G, Duan K: Isolation and characterization of two YUCCA flavin monooxygenase genes from cultivated strawberry (Fragaria $\times$ ananassa Duch.). Plant Cell Rep 2012, 31(8):1425-1435.

74. Liu K, Kang B-C, Jiang H, Moore SL, Li H, Watkins CB, Setter TL, Jahn MM: A GH3-like gene, $\mathrm{CcGH} 3$, isolated from Capsicum chinense L. fruit is regulated by auxin and ethylene. Plant Mol Biol 2005, 58(4):447-464.

75. Chung $M-Y$, Vrebalov J, Alba R, Lee J, McQuinn R, Chung J-D, Klein P, Giovannoni J: A tomato (Solanum lycopersicum) APETALA2/ERF gene, SIAP2a, is a negative regulator of fruit ripening. Plant J 2010, 64(6):936-947.

76. Karlova R, Rosin FM, Busscher-Lange J, Parapunova V, Do PT, Fernie AR, Fraser PD, Baxter C, Angenent GC, De Maagd RA: Transcriptome and metabolite profiling show that APETALA2a is a major regulator of tomato fruit ripening. Plant Cell 2011, 23(3):923-941.

77. Bajguz A, Piotrowska A: Conjugates of auxin and cytokinin. Phytochemistry 2009, 70(8):957-969.

78. Korasick DA, Enders TA, Strader LC: Auxin biosynthesis and storage forms. J Exp Bot 2013, 64(9):2541-2555

79. Chervin C, Terrier N, Ageorges A, Ribes F, Kuapunyakoon T: Influence of ethylene on sucrose accumulation in grape berry. Am J Enol Vitic 2006, 57(4):511-513.

80. Larkin MA, Blackshields G, Brown NP, Chenna R, McGettigan PA, McWilliam $H$, Valentin F, Wallace IM, Wilm A, Lopez R, et al: Clustal W and Clustal X version 2.0. Bioinformatics 2007, 23(21):2947-2948.

81. Felsenstein J: PHYLIP: Phylogeny inference package (Version 3.2). Cladistics 1989, 5:164-166.

82. Davies C, Robinson SP: Sugar accumulation in grape berries - Cloning of two putative vacuolar invertase cDNAs and their expression in grapevine tissues. Plant Physiol 1996, 111(1):275-283.

83. Symons GM, Davies C, Shavrukov Y, Dry IB, Reid JB, Thomas MR: Grapes on steroids. Brassinosteroids are involved in grape berry ripening. Plant Physiol 2006, 140(1):150-158.

84. Whelan JA, Russell NB, Whelan MA: A method for the absolute quantification of cDNA using real-time PCR. J Immunol Methods 2003, 278(1-2):261-269.

doi:10.1186/1471-2229-13-222

Cite this article as: Böttcher et al:: Interactions between ethylene and auxin are crucial to the control of grape (Vitis vinifera L.) berry ripening. BMC Plant Biology 2013 13:222. 